\title{
Canada's ehealth software "Tower of Babel"
}

Previously published at www.cmaj.ca

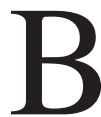
illions of dollars are being squandered in Canadian purchasing of health software for reasons of industrial policy, which is leading to disastrous technical problems and vast overpayments to technology companies and consultants, critics say.

With governments about to engage in a \$20-billion spending spree over the next decade for a national health infostructure, hundreds of Canadian and foreign companies are competing for lucrative deals to sell electronic health information systems promising to connect patients, doctors and hospitals.

But concern is growing that Canada Health Infoway and its provincial counterparts are directing the multi-billion dollar procurement process away from simple solutions based on free "opensource" software toward a multitude of pricier "proprietary-source" software products in order to stimulate Canada's software industry.

"Government procurement officials have put themselves at the mercy of the software industry," says Joseph Dal Mollin, vice president of WorldVistA, a United States software company that builds low-cost national ehealth systems based on a free software platform developed by the American government.

Dal Mollin, who also helped design OSCAR, a Canadian system based on free software, advised Infoway in 2007 to concentrate on "open-source technologies" that allow health providers to avoid paying expensive license fees to proprietary software vendors.

Taxpayer-developed open source systems such as OSCAR and VistA have been proven to outperform most proprietary systems, at a tremendous cost savings for taxpayers, Dal Mollin argues. But instead of promoting low-cost open source solutions, Infoway and the provinces have adopted policies formulated to suit "a revolving door of industry consultants who have vested interests in

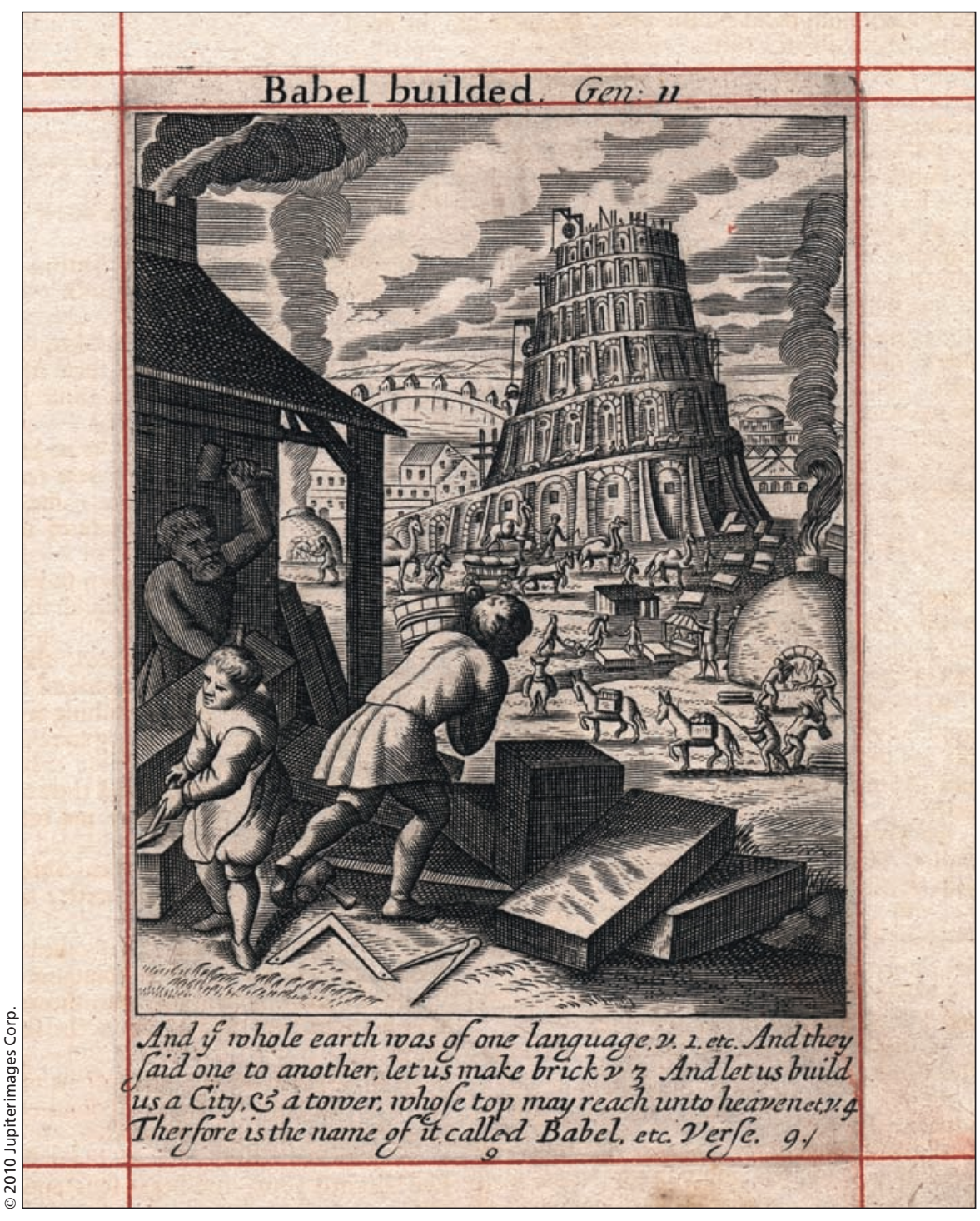

The construction of the Tower of Babel, the ehealth software equivalent of which critics say Canada is now building.

the system being overly-complicated and almost entirely proprietary.'

"As a result, we're buying a bunch of fully-proprietary systems and trying to glue them together. It's a Tower of Babel," Dal Mollin charges.

Canada's hands-off attitude toward promoting low-cost open source software for health care and other government-run services is at odds with policies in many other countries, adds Dr. David Chan, who directed the develop- ment of the OSCAR system at McMaster University in Hamilton, Ontario.

Germany, for example, recently made open-source software "the default option," he notes, adding that Canada's Parliamentary Standing Committee on Transport and Communications recently recommended that "the government follow the European example and implement pro-competitive, open access policies" for communication technologies (http://planforadigitalcanada.ca/index.php 
?option=com_content $\&$ view=article $\&$ id $=4 \&$ Itemid=13\&lang=en).

Similarly, the United Kingdom's National Programme for Information Technology found in a study that open source solutions are superior and that there is "no evidence that large-scale commercial IT systems in health care produce the benefits anticipated by their architects, and a few high quality studies suggest that they do not" (Milbank Q 2009;87[4]:729-88).

US President Barack Obama's administration, meanwhile, has shifted the White House information system onto an open source platform, while legislation passed in 2009 requires the government to review open source options for ehealth investments.

David Blumenthal, the US government's national coordinator for health information technology recently described VistA, which was designed ehealth software procurement are not evidence-based."

If Ontario adopted the taxpayerfinanced OSCAR system, doctors would have a world-leading system for one-third the cost of proprietary systems, a significant chunk of money given that the province is spending $\$ 386$ million to help as many as 9000 physicians to purchase electronic health record systems, he says.

"Costs are very low compared with proprietary systems," says Penticton, British Columbia-based Dr. Jel Coward, president of the OSCAR Canada Users Society. Coward says about 350 of the province's doctors have chosen the system even though that precludes them from obtaining provincial aid.

Using an open source product means "no-one can hold us, our data or our patients to ransom," and OSCAR outperforms proprietary systems on

\section{"We're buying a bunch of fully-proprietary systems and trying to glue them together. It's a Tower of Babel." - Joseph Dal Mollin, vice-president, WorldVistA.}

to serve 25 million patients within the Veterans Health Administration, as "a very, very capable system."

"Many countries view open source as a way to optimize the return on investment of public funds, to harness the power of a large community of innovators, and to promote the creation of jobs and the development of their own software sector," notes Alex Jadad, founder of the Centre for Global eHealth Innovation at the University Health Network in Toronto, Ontario. "It would be important to probe those responsible for major electronic health record programs in Canada in relation to their apparent aversion to open source solutions."

"Canadian governments have not been wise," Chan says. "The government procurement process is very negative on open source solutions."

That's the result of pressure from industry lobbyists and consultants, Chan adds. "Government policies on functionality and cost, Coward adds. "There has been not one commercial advertisement of OSCAR in BC that I am aware of. So OSCAR, and more importantly, the OSCAR community must be doing something right."

Moreover, the cost savings from using open source software can be significant, Chan says, pointing to a $\$ 46.2$ million contract awarded by the Ontario government to a Toronto-based software firm to build a registry of diabetes patients. That is "ridiculous," Chan says, noting a Toronto-based taxpayer-owned and operated system called Client Access to Integrated Services and Information could have built the registry for a fraction of the cost.

The Auditor General of Ontario has warned that the province's ehealth program has typically ignored input costs, such as hardware and software (www.auditor.on.ca/en/reports_en/ehealth _en.pdf).

Ehealth Ontario declined to respond to inquiries about its approach to open source software procurement options. But Matthew Anderson, chief executive officer of the William Osler Health System in Toronto, says Canada's "multisystem approach" creates avoidable costs and technical complexity while failing to achieve key clinical objectives.

"Open source relieves capital pressure," he says, whereas an unconstrained multisystem environment "is a very scary thing. You can go too far and have way too many systems."

Major urban centres could achieve huge gains from adopting single systems, he adds. "You have to ask what level of [cost] overhead are you willing to endure to provide multiple ... systems."

Canada Health Infoway spokesman Dan Strasbourg writes in an email that the agency is aware of open source options and has joined the recently formed Open Health Tools consortium, which aims to develop "a comprehensive, harmonized, open source tool suite to enable the definition, development and deployment of interoperable Electronic Health Records."

But Infoway has not pursued VistA as it is "a document-based EHR," while OSCAR cannot capture "an individual's health care across many care providers and health care locations," Strasbourg writes. Chan and Dal Morrin flatly reject those notions.

Strasbourg also writes that studies of the feasibility of large scale utilization of open source technologies are "not necessary."

Infoway's approach emphasizes benefits to the software industry, Strasbourg adds. "A rich and fair market approach, coupled with reliance on pan-Canadian standards to ensure interoperability, will help to ensure interoperability [and] will help ensure the long-term viability of Canada's complex and innovative EHR community."

The software industry itself is not averse to open sources solutions, says Brendan Seaton, head of the Informational Technology Association of Canada's health division. He adds that governments are doing "a fine job" managing ehealth procurement. — Paul Christopher Webster, Toronto, Ont. 